\title{
Efficacy of Food Fortification with Vitamin D in Iranian Adults: A Systematic Review and Meta-Analysis
}

\author{
Bahareh Nikooyeh $^{1}$, Tirang R. Neyestani ${ }^{1 *}$ \\ 1- Laboratory of Nutrition Research, National Nutrition and Food Technology Research Institute and Faculty of Nutrition Sciences and Food \\ Technology, Shahid Beheshti University of Medical Sciences, Tehran, Iran.
}

\begin{abstract}
A B S T R A C T
There are a number of reports showing high prevalence of hypovitaminosis D across Iran. The objective of this study was to evaluate whether food fortification with vitamin D has the potential to increase serum 25(OH)D concentrations in Iranian people. MEDLINE, PubMed, EMBASE, and The Cochrane Central Register of Controlled Trials were searched for randomized controlled clinical trials involvingIranian participants to assess the effect of fortified food either with vitamin D2 or D3 (with or without calcium) versus control on serum $25(\mathrm{OH}) \mathrm{D}$ concentrations. Four studies used dairy products as a food source and bread was used in one experiment. The daily dose of vitamin D3, 1000 and $2000 \mathrm{IU}$, and the duration of administration ranged from 8 to 12 weeks. The moderate heterogeneity was detected across the included studies $\left(\mathrm{P}<0.00001 ; \mathrm{I}^{2}=55 \%\right)$.Using a random effects analysis $(\mathrm{n}=193)$, the efficacy effect was $34.6 \mathrm{nmol} / \mathrm{L}$ (95\% CI: 28.6 , 40.8). The present meta-analysis showed that food fortification with vitamin D could be an effective tool to prevent and control hypovitaminosis D and Iranian population will most probably benefit from the vitamin D fortification as a national policy.
\end{abstract}

Keywords: Fortification, Vitamin D, Iran

\section{Introduction}

Hypovitaminosis $\mathrm{D}$ has been shown to be very common in the population around the world and this problem is a public health issue affecting all sex, age and economic subgroups. On the other hand, A burgeoning body of research has suggested the link between vitamin $\mathrm{D}$ status and risks of many chronic diseases including autoimmune disorders, cardiovascular diseases, cancers and diabetes (1).

Circulating concentrations of 25-hydroxycalciferol $(25(\mathrm{OH}) \mathrm{D})$ is the best indicator of vitamin D status reflecting combined contributions of both the diet and sunlight exposure (2).The majority of circulating $25(\mathrm{OH}) \mathrm{D}$ comes from the cutaneous synthesis under the action of sunlight (80-90\%) (3). However, for the reason that so many environmental, cultural, and physiologic factors including latitude of living place, season, gender and obesity can influence cutaneous synthesis of vitamin $\mathrm{D}$, reliance on intake is indispensable (4).
There are a number of reports showing high prevalence of hypovitaminosis D across Iran. The National Food and Nutrition Surveillance (NFNS) assessed vitamin D status in a population sample of persons from 5 to 65 years including latitudes from $29 \circ$ to higher than $37^{\circ}$, reported that hypovitaminosis $\mathrm{D}$ is very common in Iranian population and more than $90 \%$ of population had undesirable vitamin D status (serum25(OH)D <50nmol/1) (5-6).

Natural sources of vitamin D in Iranian diet are rare. The Iranian population is, therefore, largely dependent on subcutaneous synthesis of vitamin D. However, NFNS showed that even sunlight in summertime cannot guarantee optimal vitamin D status (7).To address the issue of vitamin D deficiency in the general population in Iran, the Ministry of Health started evaluating different aspects of mass fortification of staple foods as an appropriate public health strategy. Indeed in many countries fortified foods, including milk, bread, yogurt, cheese, 
margarine and orange juice constitute the major dietary sources of vitamin $\mathrm{D}(8)$. The objective of this study was to evaluate whether food fortification with vitamin $\mathrm{D}$ has the potential to increase serum $25(\mathrm{OH}) \mathrm{D}$ concentrations in Iranian people.

\section{Materials and Methods}

Search strategy: The research team searched multiple databases, including MEDLINE, PubMed, EMBASE, and The Cochrane Central Register of Controlled Trials. The team restricted the studies to those published in English/Persian and involving human participants. The team only included studies that assessed the effect of fortified food either with vitamin D2 or D3 (with or without calcium) versus control on serum $25(\mathrm{OH}) \mathrm{D}$ concentrations and in Iranian participants. The search utilized the keywords "vitamin D," "cholecalciferol", "fortified", "fortification", "25(OH)D", "25hydroxycholecalciferol". The data extracted from each study were name of first author, year of publication, used vehicle, dose of fortificant and mean of $25(\mathrm{OH}) \mathrm{D}$ in baseline and endpoint of intervention in control and intervention groups. The exposure and outcome were intake of vitamin D via fortified food and circulating $25(\mathrm{OH}) \mathrm{D}$, respectively.

Risk of Bias Assessment: The quality and bias risk of the included studies were evaluated by two authors independently, with disagreements were resolved by consensus. (27) and the Jadad scoring scale (28) were used to assess the methodological quality of the included RCTs. The bias risk assessment tool recommended by the Cochrane Handbook for Systematic Reviews of Interventions, version 5.1.0 (9) and oxford quality scoring system (Jadad scale) (10) were utilized in order to assess the risk of bias of each study.

Statistical analysis: All analyses were conducted using Review Manager Version 4.3 (Revman; The Cochrane Collaboration, Oxford, UK). The absolute change values for control and intervention groups were used to estimate overall efficacy effects that were defined as the mean difference. In addition to forest plots, the $\mathrm{I}^{2}$ statistic of inconsistency was used to assess statistical heterogeneity. An $\mathrm{I}^{2}$ of 25,50 , and $75 \%$ were defined as low, moderate, and high heterogeneity, respectively(11).

For standardization of results of different assay methods, harmonization methods were used (12).

\section{Results}

The searches in June 2018 yielded 13 papers. Eight of them were excluded after initial screening of the titles and abstracts and removal of duplicates (Fig. 1). A total of 5 clinical trials (13-17) involving 59 to 101 participants (Table 1). All studies were conducted in adult populations. Four studies were conducted in participants with type 2 diabetes $(13-15,18)$ and 1 in women only (17). Four studies used dairy products $(13,15,17-18)$ as a food source and bread was used in one experiment (14). The daily dose of vitamin D3, 1000 and $2000 \mathrm{IU}$, and the duration of administration ranged from 8 to 12 weeks. Three studies used HPLC (high pressure liquid chromatography) to measure serum $25(\mathrm{OH}) \mathrm{D}(13-14,18)$ and two studies used ELISA (enzyme linked immunosorbent assay) (15, 17). All studies scored $\geq 3$ on the Jadad scale. Moreover, we judged all studies at low risk of bias using Cochrane tools. Foods, doses, and serum $25(\mathrm{OH}) \mathrm{D}$ concentrations are presented in Table1.

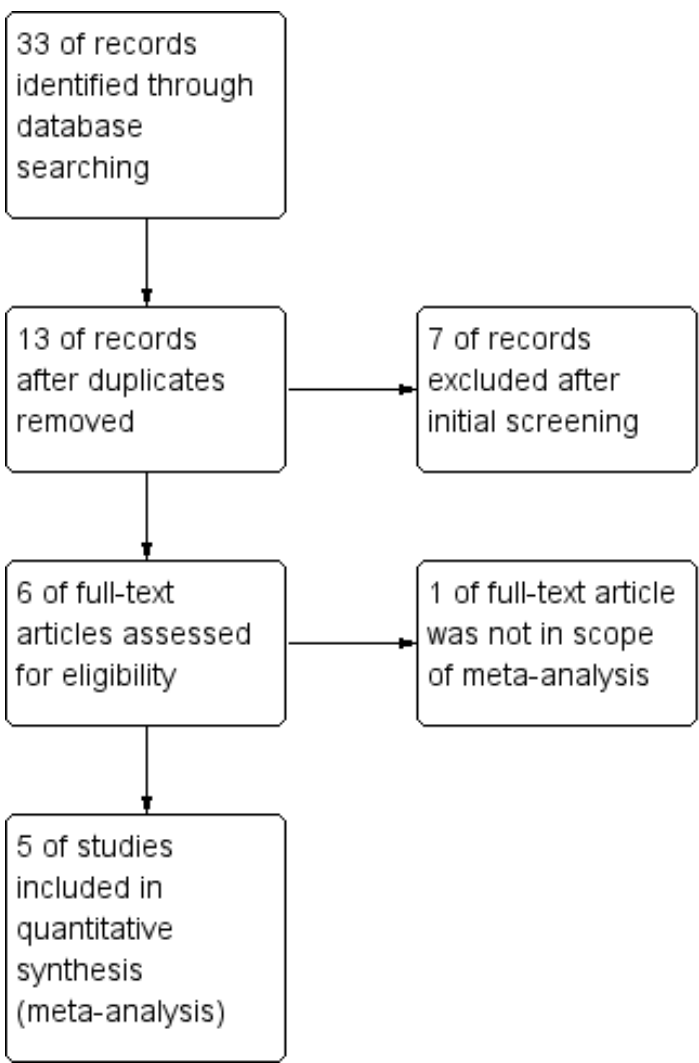

Figure 1. Study flow chart 


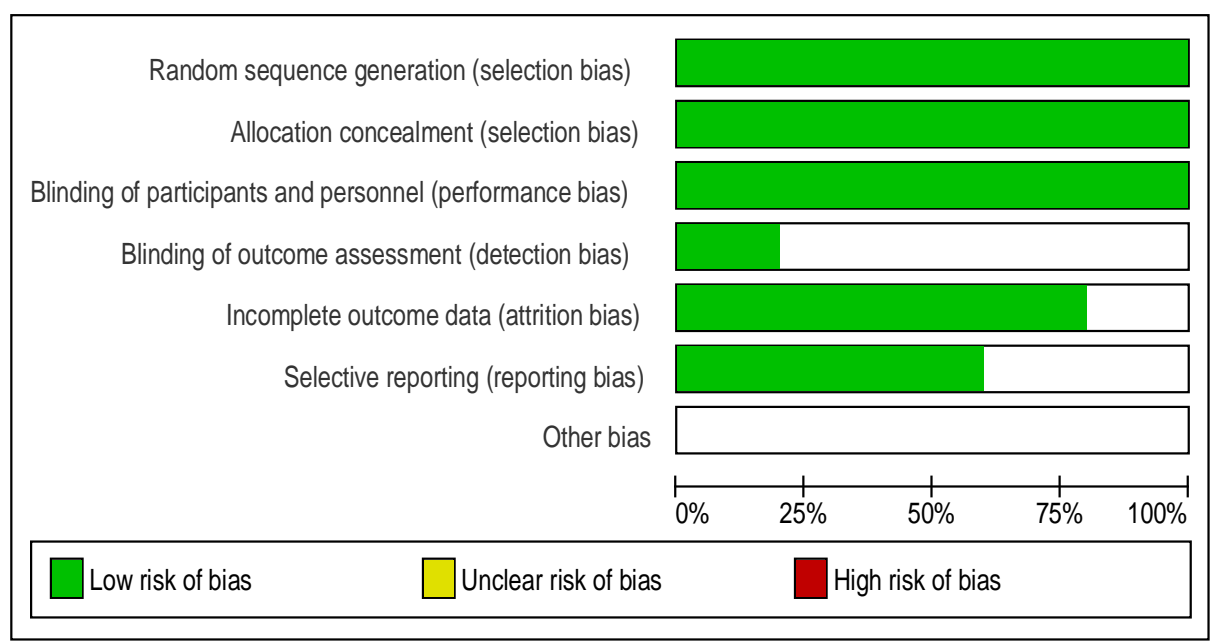

Figure 2. Risk of bias graph: review authors' judgements about each risk of bias item presented as percentages across all included studies.

Table1. Characteristics, foods, doses and serum 25(OH)D concentrations of studies

\begin{tabular}{|c|c|c|c|c|c|c|c|c|c|c|c|c|}
\hline & \multirow[b]{2}{*}{$\begin{array}{l}\text { Age } \\
(\mathrm{yr})\end{array}$} & \multirow[b]{2}{*}{$\begin{array}{l}\text { Food } \\
\text { carrier }\end{array}$} & \multicolumn{2}{|c|}{ control } & \multirow[b]{2}{*}{$\mathrm{n}$} & \multicolumn{2}{|c|}{ Intervention } & \multirow[b]{2}{*}{$\begin{array}{l}\text { Added } \\
\text { vitamin } \\
\text { D (IU) }\end{array}$} & \multirow[b]{2}{*}{$\mathrm{n}$} & \multirow[b]{2}{*}{ Duration } & \multirow[b]{2}{*}{ Method } & \multirow[b]{2}{*}{ Location } \\
\hline & & & $\begin{array}{l}\text { Endpoint } \\
25(\mathrm{OH}) \mathrm{D} \\
(\mathrm{nmol} / \mathrm{L})\end{array}$ & $\begin{array}{l}\text { Baseline } \\
25(\mathrm{OH}) \mathrm{D} \\
(\mathrm{nmol} / \mathrm{L})\end{array}$ & & $\begin{array}{l}\text { Endpoint } \\
25(\mathrm{OH}) \mathrm{D} \\
(\mathrm{nmol} / \mathrm{L})\end{array}$ & $\begin{array}{l}\text { Baseline } \\
25(\mathrm{OH}) \mathrm{D} \\
(\mathrm{nmol} / \mathrm{L})\end{array}$ & & & & & \\
\hline $\begin{array}{l}\text { Nikooyeh, et } \\
\text { al, 2011, (13) }\end{array}$ & $30-60$ & $\begin{array}{l}\text { Yogurt } \\
\text { drink }\end{array}$ & $37.2 \pm 44$ & $41.6 \pm 44.5$ & 30 & $77.7 \pm 28.6$ & $44.4 \pm 28.7$ & 1000 & 30 & 12 wk & HPLC & Tehran \\
\hline $\begin{array}{l}\text { Nikooyeh, et } \\
\text { al, 2016, (14) }\end{array}$ & $20-60$ & Bread & $25.4 \pm 21.8$ & $34.7 \pm 30.5$ & 30 & $72.9 \pm 23.1$ & $33.9 \pm 21.9$ & 1000 & 30 & $8 \mathrm{wk}$ & HPLC & Tehran \\
\hline $\begin{array}{l}\text { Salehi, et al, } \\
2018 \text { (15) }\end{array}$ & $31-74$ & milk & $50.0 \pm 42.5$ & $40.0 \pm 30.0$ & 50 & $77.5 \pm 47.5$ & $42.5 \pm 27.5$ & 1000 & 51 & $9 \mathrm{wk}$ & ELISA & Shiraz \\
\hline $\begin{array}{l}\text { Shab-bidar, et } \\
\text { al, 2011, (18) }\end{array}$ & $20-60$ & $\begin{array}{l}\text { Yogurt } \\
\text { drink }\end{array}$ & $33.4 \pm 22.8$ & $38.0 \pm 22.8$ & 50 & $72.0 \pm 23.5$ & $38.5 \pm 20.2$ & 1000 & 50 & $12 \mathrm{wk}$ & HPLC & Tehran \\
\hline $\begin{array}{l}\text { Jafari, et al, } \\
2015 \text { (17) }\end{array}$ & $>50$ & Yogurt & $56.1 \pm 2.8$ & $62.7 \pm 4.2$ & 29 & $86.8 \pm 4.8$ & $62.2 \pm 4.5$ & 2000 & 30 & $12 \mathrm{wk}$ & ELISA & Isfahan \\
\hline
\end{tabular}

The outcome variable of interest was circulating $25(\mathrm{OH}) \mathrm{D}$ as the best marker of vitamin D status. The moderate heterogeneity was detected across the included studies $\left(\mathrm{P}<0.00001 ; \mathrm{I}^{2}=55 \%\right)$. Using a random effects analysis $(\mathrm{n}=193)$ (Fig. 3), the efficacy effect was $34.6 \mathrm{nmol} / \mathrm{L}$ (95\% CI: 28.6, 40.8).

Four studies out of five used daily dose of $25 \mu \mathrm{g} / \mathrm{d}$, heterogeneity was $44 \%$ in those studies. $(13-15,18)$. The overall efficacy effect was $37.1 \mathrm{nmol} / \mathrm{L}(95 \% \mathrm{CI}$, 28.6-45.7), relating to a $1.4 \mathrm{nmol} / \mathrm{L}$ increase in 25(OH)D for each $1 \mu \mathrm{g} / \mathrm{d}$ ingested. We were not able to further subgroup analysis, due to the small number of studies.

Though circulating $25(\mathrm{OH}) \mathrm{D}$ is the commonly accepted biomarker for vitamin D status, there is no agreement among different methods(19-20). To address this issue, we used the equations to harmonize the results obtained from different assay systems (12). By using these equations, the efficacy effect was 36.8 nmol/L (95\% CI: 32.3, 41.2). There was a low level of heterogeneity across the 5 studies $(\mathrm{P}<0.00001$; $\left.\mathrm{I}^{2}=13 \%\right)$ (Figure 4.) 


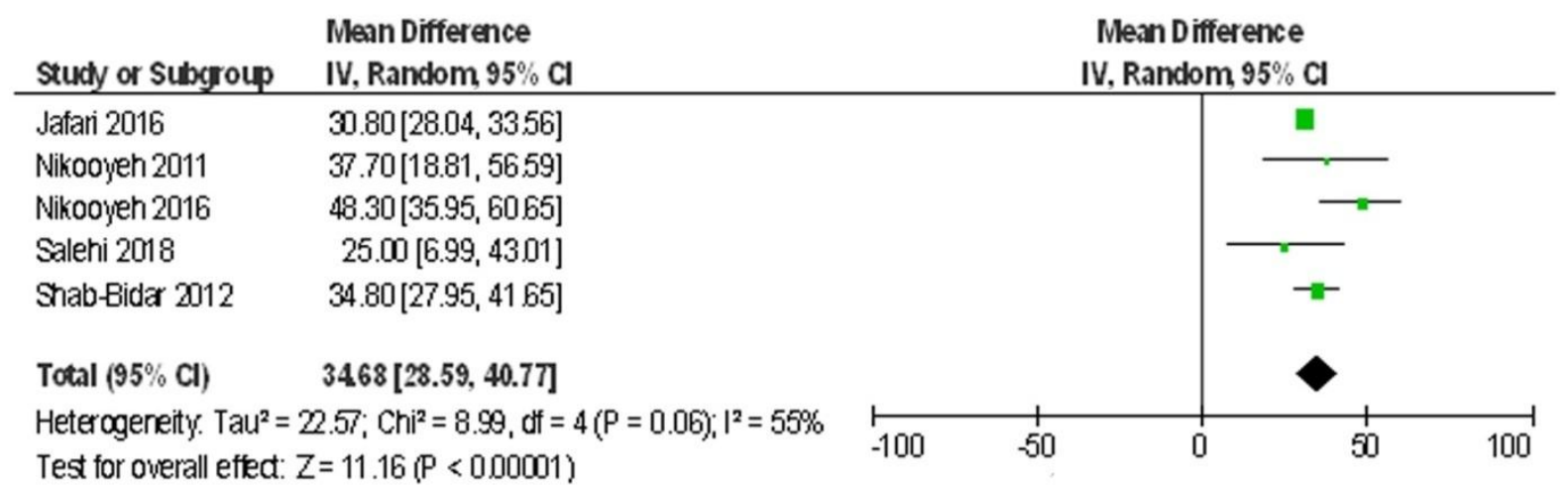

Figure 3. Weighed mean differences in serum $25(\mathrm{OH}) \mathrm{D}$ concentrations $(\mathrm{nmol} / \mathrm{L})$

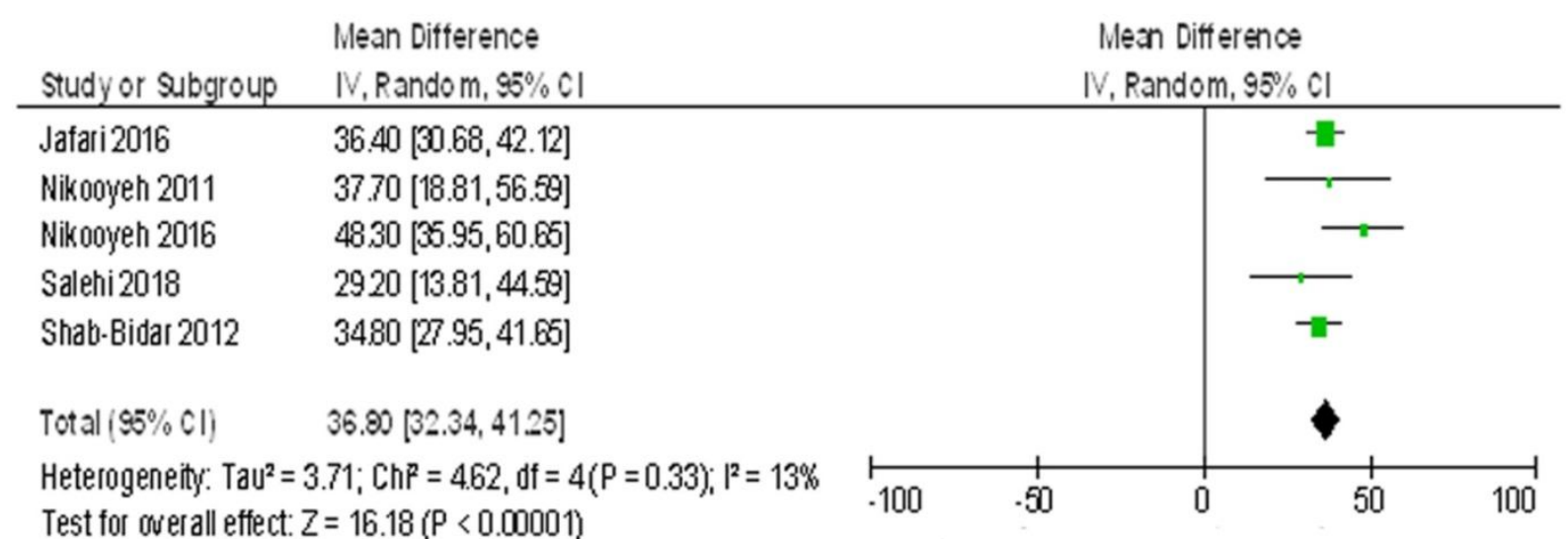

Figure 4. Weighed mean differences in serum $25(\mathrm{OH}) \mathrm{D}$ concentrations $(\mathrm{nmol} / \mathrm{L})$ after harmonization of results

\section{Disc ussion}

The results of present meta-analysis demonstrate that vitamin D fortification substantially improved the vitamin D status. All studies were successful at improving vitamin D status and none of them reported clinical or laboratory evidence of toxicity.

There have been several reports detailing the prevalence for vitamin D deficiency across Iran. Recently, National Food and Nutrition Surveillance reported that above $90 \%$ of Iranian population had hypovitaminosis $\mathrm{D}$ in winter $(5,21)$. There are a few strategies available to improve vitamin D status in population. Food-based strategies are of considerable importance in protecting against vitamin D deficiency, in particular when sun exposure is low or limited due to environmental, cultural and/or individual characteristics. As the natural dietary sources of vitamin D are limited, the high occurrence of undesirable vitamin D status among Iranian population is not surprising(22).Vitamin D supplements can increase serum 25(OH)D concentrations across population subgroups undoubtedly(23). However, this strategy cannot be used for a long time and for the majority of the population(24).

Vitamin D fortification of foods either mandatory or voluntary has been suggested as a strategy to improve $25(\mathrm{OH}) \mathrm{D}$ levels significantly in the population(25). Many countries have added vitamin $\mathrm{D}$ to foods such as milk products, bread, and orange juice as a main strategy to combat hypovitaminosis D. In Finland, vitamin D has been added to liquid milk products $(0.5 \mu \mathrm{g} / \mathrm{dL})$, as well as margarines and butter $(10 \mu \mathrm{g} / 100 \mathrm{~g})$ from 2003. Reports showed that national vitamin $\mathrm{D}$ fortification substantially improved the vitamin D status (26). In Canada, the foods that require fortification with vitamin $\mathrm{D}$ are milk products (400 IU/ 250mL) and margarine (530 IU/100g)(27). However, studies suggested that current fortification programs in Canada are not successful in preventing undesirable status of vitamin $\mathrm{D}$, particularly among at risk populations during winter time (28-29). In fortification programs 
milk products, bread, orange juice, vegetable oils and margarine have been used as a fortification vehicle for vitamin D (26-27, 30). Some evidence showed that milk can be an effective vehicle for fortification(30). However, several national and sporadic reports have shown that milk is not adequately consumed in $\operatorname{Iran}(31)$. Alternatively, staple foods such as bread and oil could be used to improve vitamin D status of the general population. The Optimal Fortification with vitamin D (OPTIFORD) European project examined the possibility of fortification as a strategy for improving vitamin D status and revealed that the high potential of bread as a safe and practical vehicle for fortification(32).

In those studies, that used dose of $25 \mu \mathrm{g} /$ day, the efficacy effect was $37.1 \mathrm{nmol} / \mathrm{L}$ (95\% CI, 28.6-45.7), on average, $1.4 \mathrm{nmol} / \mathrm{L}$ increase in serum $25(\mathrm{OH}) \mathrm{D}$ concentrations for each $1 \mu \mathrm{g} / \mathrm{d}$ ingested. Previous studies also reported that $1 \mu \mathrm{g}$ of ingested vitamin D can increase $25 \mathrm{OHD}$ concentration by 1

to $1.2 \mathrm{nmol} / \mathrm{L}(33)$.

Noteworthy, disagreement among different systems of $25(\mathrm{OH}) \mathrm{D}$ assay is another challenge(34). Large discrepancies among the results obtained from different assay methods make national comparisons of the prevalence of suboptimal status of vitamin D extremely difficult (12).Consequently, suggested harmonization methods were used for comparison of assay results(12).This resulted in increment of overall efficacy effect and a decrement in heterogeneity across the studies.

The risk of bias in all trials was low and the statistical heterogeneity was low to medium based on the $\mathrm{I}^{2}$ statistic of inconsistency. In addition, there was no difference in the dose of used vitamin $\mathrm{D}$, and the intervention duration in most studies.

However, there were some limitations in this meta-analysis. Due to limited studies, we were not able to subgroup analysis for example for dose of vitamin D and type of vehicles. Also we could not exclude other possible unmeasured confounders in this meta-analysis.

\section{Conclusion}

It is essential to combat vitamin D deficiency via appropriate strategies in Iran. Present meta-analysis showed that food fortification with vitamin D could be an effective tool to prevent and control hypovitaminosis D and Iranian population will most probably benefit from the vitamin $\mathrm{D}$ fortification as a national policy. Vitamin D food fortification policies in Iran are regulated by Ministry of Health. At this time, there is no program for mandatory vitamin $\mathrm{D}$ fortification of foods in Iran. Overall, if policymakers decide to support national programs of fortification with vitamin $\mathrm{D}$, bread, milk and dairy products could be appropriate vehicles.

\section{Financial disclosure}

The authors declared no financial interest.

\section{References}

1. Holick MF. The vitamin D epidemic and its health consequences. J Nutr. 2005 Nov;135(11):2739S-48S.

2. Weaver CM, Fleet JC. Vitamin D requirements: current and future. The American Journal of Clinical Nutrition. 2004;80(6):1735S-9S.

3. Holick MF. Deficiency of sunlight and vitamin D. BMJ: British Medical Journal. 2008;336(7657):1318.

4. Holick MF. Vitamin D: the underappreciated D-lightful hormone that is important for skeletal and cellular health. Current Opinion in Endocrinology, Diabetes and Obesity. 2002;9(1):87-98.

5. Nikooyeh B, Abdollahi Z, Hajifaraji M, Alavi-Majd H, Salehi F, Yarparvar AH, et al. Vitamin D status, latitude and their associations with some health parameters in children: National Food and Nutrition Surveillance. Journal of Tropical Pediatrics. 2016;63(1):57-64.

6. Nikooyeh B, Abdollahi Z, Hajifaraji M, Alavi-majd H, Salehi F, Yarparvar AH, et al. Vitamin D status and cardiometabolic risk factors across latitudinal gradient in Iranian adults: National food and nutrition surveillance. Nutrition and Health. 2017;23(2):87-94.

7. Nikooyeh B, Abdollahi Z, Hajifaraji M, Alavi-Majd H, Salehi F, Yarparvar AH, et al. Healthy changes in some cardiometabolic risk factors accompany the higher summertime serum 25-hydroxyvitamin D concentrations in Iranian children: National Food and Nutrition Surveillance. Public Health Nutrition. 2018:1-9.

8. Calvo MS, Whiting SJ, Barton CN. Vitamin D intake: a global perspective of current status. The Journal of Nutrition. 2005;135(2):310-6.

9. Higgins J. Green S. Cochrane handbook for systematic reviews of interventions Version 5.1. 0. The Cochrane Collaboration. Confidence intervals. 2011.

10. Jadad AR, Moore RA, Carroll D, Jenkinson C, Reynolds DJM, Gavaghan DJ, et al. Assessing the quality of reports of randomized clinical trials: is blinding necessary? Controlled Clinical Trials. 1996;17(1):1-12.

11. Higgins JP, Thompson SG, Deeks JJ, Altman DG. Measuring inconsistency in meta-analyses. BMJ: British Medical Journal. 2003;327(7414):557.

12. Nikooyeh B, Samiee SM, Farzami MR, Alavimajd H, Zahedirad M, Kalayi A, et al. Harmonization of serum 25-hydroxycalciferol assay results from highperformance liquid chromatography, enzyme immuno- 
assay, radioimmunoassay, and immunochemiluminescence systems: A multicenter study. Journal of clinical laboratory analysis. 2017;31(6).

13. Nikooyeh B, Neyestani TR, Farvid M, Alavi-Majd H, Houshiarrad A, Kalayi A, et al. Daily consumption of vitamin D- or vitamin D + calcium-fortified yogurt drink improved glycemic control in patients with type 2 diabetes: a randomized clinical trial. Am J Clin Nutr.2011 Apr;93(4):764-71.

14. Nikooyeh B, Neyestani TR, Zahedirad M, Mohammadi M, Hosseini SH, Abdollahi Z, et al. Vitamin D-Fortified Bread Is as Effective as Supplement in Improving Vitamin D Status: A Randomized Clinical Trial. J Clin Endocrinol Metab.2016 Jun;101(6):2511-9. doi(2016 Apr 26):10.1210/jc.2016-1631.

15. Salehi S, Sadeghi F, Akhlaghi M, Hanifpour MA, Roshanzamir M. Vitamin D3-fortified milk did not affect glycemic control, lipid profile, and anthropometric measures in patients with type 2 diabetes, a triple-blind randomized clinical trial. Eur J Clin Nutr.2018 Jan 11. pii(10):10.1038/s41430-017-0062-1.

16. Shab-Bidar S, Neyestani TR, Djazayery A, Eshraghian MR, Houshiarrad A, Kalayi A, et al. Improvement of vitamin D status resulted in amelioration of biomarkers of systemic inflammation in the subjects with type 2 diabetes. Diabetes Metab Res Rev.2012 Jul;28(5):42430. doi(2012 Feb 17):10.1002/dmrr. 2290.

17. Jafari T, Faghihimani E, Feizi A, Iraj B, Javanmard SH, Esmaillzadeh A, et al. Effects of vitamin D-fortified low fat yogurt on glycemic status, anthropometric indexes, inflammation, and bone turnover in diabetic postmenopausal women: A randomised controlled clinical trial. Clin Nutr.2016 Feb;35(1):67-76. doi(2015 Mar 5):10.1016/j.clnu.2015.02.014.

18. Shab-Bidar S, Neyestani TR, Djazayery A, Eshraghian M-R, Houshiarrad A, Gharavi Aa, et al. Regular consumption of vitamin D-fortified yogurt drink (Doogh) improved endothelial biomarkers in subjects with type 2 diabetes: a randomized double-blind clinical trial. BMC medicine. 2011;9(1):125.

19. Ong L, Saw S, Sahabdeen NB, Tey KT, Ho CS, Sethi SK. Current 25-hydroxyvitamin D assays: do they pass the test? Clin Chim Acta. 2012 Jul 11;413(13-14):112734.

20. Binkley N, Sempos CT. Standardizing vitamin D assays: the way forward. J Bone Miner Res. 2014 Aug;29(8): 1709-14.

21. Nikooyeh B, Abdollahi Z, Hajifaraji M, Alavi-majd H, Salehi F, Yarparvar AH, et al. Vitamin D status and cardiometabolic risk factors across latitudinal gradient in Iranian adults: National food and nutrition surveillance. Nutrition and Health. 2017:0260106017702918.

22. Nikooyeh B, Neyestani TR, Farvid M, Alavi-Majd H, Houshiarrad A, Kalayi A, et al. Daily consumption of vitamin D- or vitamin D + calcium-fortified yogurt drink improved glycemic control in patients with type 2 diabetes: a randomized clinical trial. Am J Clin Nutr. 2011 Apr;93(4):764-71.

23. Autier P, Gandini S, Mullie P. A systematic review: influence of vitamin D supplementation on serum 25hydroxyvitamin D concentration. The Journal of Clinical Endocrinology \& Metabolism. 2012;97(8):2606-13.

24. Dwyer JT, Coates PM, Smith MJ. Dietary Supplements: Regulatory Challenges and Research Resources. Nutrients. 2018 Jan 4;10(1).

25. Wilson LR, Tripkovic L, Hart KH, Lanham-New SA. Vitamin D deficiency as a public health issue: using vitamin D 2 or vitamin D 3 in future fortification strategies. Proceedings of the Nutrition Society. 2017;76(3):392-9.

26. Laaksi IT, Ruohola JS, Ylikomi TJ, Auvinen A, Haataja RI, Pihlajamäki HK, et al. Vitamin D fortification as public health policy: significant improvement in vitamin D status in young Finnish men. European Journal of Clinical Nutrition. 2006;60(8):1035.

27. Calvo MS, Whiting SJ, Barton CN. Vitamin D fortification in the United States and Canada: current status and data needs. The American journal of clinical nutrition. 2004;80(6): 1710S-6S.

28. Rucker D, Allan JA, Fick GH, Hanley DA. Vitamin D insufficiency in a population of healthy western Canadians. Canadian Medical Association Journal. 2002;166(12):1517-24.

29. Vieth R, Cole D, Hawker G, Trang H, Rubin L. Wintertime vitamin D insufficiency is common in young Canadian women, and their vitamin D intake does not prevent it. European Journal of Clinical Nutrition. 2001;55(12):1091.

30. Chee W, Suriah A, Chan S, Zaitun Y, Chan Y. The effect of milk supplementation on bone mineral density in postmenopausal Chinese women in Malaysia. Osteoporosis International. 2003;14(10):828-34.

31. Esfarjani F, Mohammadi-Nasrabadi F, Roustaee R, Khalafi M, Alikhanian H, NouriSaeidlou S, et al. Household Milk consumption and Its Socio-economic Associates in West Azarbayejan Province, North-west Iran. Nutr Food Sci Res. 2015;2(3):21-7.

32. Natri A-M, Salo P, Vikstedt T, Palssa A, Huttunen M, Kärkkäinen MU, et al. Bread fortified with cholecalciferol increases the serum 25-hydroxyvitamin $\mathrm{D}$ concentration in women as effectively as a cholecalciferol supplement. The Journal of Nutrition. 2006;136(1):123-7.

33. Black LJ, Seamans KM, Cashman KD, Kiely M. An updated systematic review and meta-analysis of the efficacy of vitamin D food fortification. J Nutr. 2012 Jun;142(6):1102-8.

34. Hollis BW. Comparison of commercially available (125)I-based RIA methods for the determination of circulating 25-hydroxyvitamin D. Clin Chem. 2000 Oct;46(10):1657-61. 